\title{
BICENTENÁRIO DE JOAQUIM LE BRETON, CHEFE DA MISSÃO ARTÍSTICA FRANCESA DE 1816.
}

Comemora-se neste ano o bicentenário de nascimento de Joaquim Le Breton, crítico de arte francês, tão característico do neoclassicismo estético de sua época e ligado ao nosso país por nele haver fundado uma Escola de Arte.

Nascido aos 7 de abril de 1760 em Saint-Meen de Gael na Bretanha, foi o chefe e idealizador da Missão Artística de 1816, que veio para o Rio de Janeiro contratada por D. João VI, a fim de criar-se a Escola Real de Ciências, Artes e Ofícios, posteriormente denominada Academia Imperial de Belas Artes e hoje Escola Nacional de Belas Artes.

Autor de volumoso Relatório, apresentado a Napoleão em 1808, sôbre o desenvolvimento das Artes na França, a partir de 1789, escreveu também elogios dos escultores Julien, Pajou, Moitte e Claudet, dos compositores Haydn e Gretry, do pintor Vien e de 'outros artistas. Foi secretário perpétuo da classe de Belas Artes do Instituto de França, tendo conhecido Alexandre de Humboldt e outras personalidades de sua época.

Sua biografia e as causas de sua vinda para o Brasil foram, em nosso idioma, estudadas pelo historiadores Afonso d'Escragnole Taunay em seu trabalho A Missão Artística de 1816, cuja 1a. edição é de 1911, vinda à luz na Revista do Instituto Histórico e Geográfico Brasileiro, LXXIV, 3. A segunda, com modificações, constitui a publicação n. ${ }^{\circ} 18$ da Diretoria do Patrimônio Histórico e Artístico Nacional (1).

Em 1911, Taunay insistira em dizer que a idéia da criação da Escola nascera de portuguêses e brasileiros. Todavia, em 1956 já reconhece, baseado em documentos diplomáticos lusos, que fêz copiar em Portugal, que o idealizador da Missão e da Escola fôra Le Breton, em Paris.

(1). - Ministério da Educação e Cultura: Rio de Janeiro, 1956. Nesta edição, o capítulo com traços biográficos de Le Breton vem nas págs. 54-73. 
O Secretário Perpétuo da Classe das Belas Artes do Instituto da França estava em 1815 às vésperas de ver esvair-se a sua perpetuidade ao ser demitido do cargo que ocupava.

Em outubro de 1814 e de 1815, transcorreram cheias de incidentes, solenidades públicas anuais do Instituto, já no novo regime bourbônico, então recentemente restaurado. Admirador de Bonaparte, Le Breton viu-se envolvido nos acontecimentos, tendo feito em seu discurso alusões que desagradaram ao que parece, a Lord Wellington, presente a primeira cerimônia e a Luís XVIII, tanto sôbre a devolução de obras de arte recolhidos ao Louvre, como, a respeito 'de outros assuntos artísticos.

Tratou, então, de organizar a missão que viria ao Brasil criar uma Escola de Artes, pedant no sul do Continente da Escola do México, elogiado por Humboldt. João Batista Debret confirma essa emulação na dedicatória ao Instituto de França de sua Viagem Pitoresca.

Marcel Bonnaire, na obra Procés Verbaux de l'Academie des Beaux Arts, da qual foram publicados pela Sociedade de História da Arte Francesa, três tomos: o primeiro em 1937, os segundo e terceiro em 1940 e 1943 (2), dá as seguintes indicações sôbre Le Breton: intelectual revolucionário de 1789, político e esteta:

"Crítico de Arte". Em 1790, Procurador-Síndico do Distrito de Fougères. 1791-1795, Deputado de "IIIe-et-Villaine". 1795-1798, Membro do Conselho dos 500. "Eleito membro do Instituto - II Classe (1a. Secção) Análise das Sensações e das Idéias" em 14-XII-1795. Passou à 3a. Classe em 28-1-1803. E adiante: "Excluido por Ordem de 21 de março de 1816, por ter protestado contra a retirada dos objetos de arte de nossos museus e sua restituição a estrangeiros" (3).

A eleição para Secretário Perpétuo da classe de Belas Artes efetuou-se aos 5 de fevereiro de 1803 . Fôra êle também associado (da classe?) segundo se depreende da ata de 17-IV-1796, publicada por M. Bonnaire. (Tomo I, p. 15), que informa:

"O cidadão Le Breton, associado, escreve de Besançon que ali se venderam as "Tapeçarias dos Atos Apóstolos, segundo cartões de Rafael"; propõe que as compre o Govêrno. Decidiu-se agradecer a êste associado e de responder-lhe que, só em Paris, existem várias coleçõeș destas Tapeçarias".

(2). — Edlção Librairie Armand Colin, Paris.

(3). - Op. cit., tomo II, págs. 135-136. 
Tratar-se-á de Joaquim Le Breton ou de outro Le Breton? Deve ser o mesmo. Afonso d'Escragnole Taunay fala, aliás, de vários serviços que Le Breton teria prestado à antiga classe de Belas Artes, antes de ser eleito secretário da mesma. De qualquer modo a fina e sútil lição dos veteranos artistas reunidos no Instituto dirigia-se a um estudioso, que anda iria enriquecer a sua experiência, inclusive 'através de informações dêsse tipo.

Coincidindo com as observações que qualquer conhecedor da História da Arte do período Neoclássico poderá fazer, M. Bonnaire no tomo III de sua obra (pp. 152-153) sintetiza o relatório apresentado a Napoleão, em seu Conselho de Estado, escrevendo a respeito o seguinte:

"A deputação da classe foi apresentada ao Imperador, em seu Conselho de Estado, aos 5 de março de 1808, por Cretet, ministro do Interior. Depois do discurso do Presidente, o Secretário Perpétuo, Le Breton, em uma alocução, resumiu o conteúdo geral das artes dos últimos vinte anos; ela fornece um julgamento sôbre os artistas dêste perício, que a posteridade ratificou no seu conjunto. Em segulda faz uma volta aos séculos XVII e XVIII, rendendo homenagem aos Filipe de Champaigne, Le Sueur, Poussin, Mignard, Puget, Coysevox, a Luís XIV, a Colbert, protetores esclarecidos das artes. Mas estima que Versailes teria sido mais perfeito se os artistas tivessem se submetido menos ao talento e à maneira de Le Brun. A classe é bastante dura para com os artista do Reino de Luís XV; o pintor Boucher e sua influência na Escola fixam o último periodo da decadência; a escultura é "bárbara"; a arquitetura tornada mesquinha, isobrecarrega-se de ornamentos ridículos. Ela rende a merecida homenagem a Vien que ousando tomar por guia os estudos da natureza e do antigo, não se apresentando como reformador, sem barulho e exagêro, guiando Vincent, Menageot, David, Regnalt, influenciando os escultores Julien, Houdon, Pajou, Dejoux, Roland, Moitte; sustentando por d'Angiviller operou desde antes de 1789 o soerguimento que se impunha. Joseph Vernet merece o elogio de "pintor mais perfeito do século; e que se pode esperar a sua substituição, senão de um favor particular da natureza". Ver Institut de France. Classe des Beaux-Arts. Rapport histórique sur les progrés des arts depuis 1789. 1 vol., in 4. 240 pp.".

$\mathrm{Na}$ comunicação que fiz ao XIX Congresso Internacional de História da Arte, intitulada Le Breton et l'organisation d'une double école des Beaux Arts et des Arts-Metiers au Brésil en 
1816, abordei, em 1958, êsses aspectos do Relatório, que confirmavam a visão enfàticamente neoclássica de Le Breton e comprovam as dificuldades de compreensão com que iria naturalmente encarar a arte barrôca do Rio de Janeiro.

Provei então, também, que a grafia de seu sobrenome era Le Breton, em partes separadas, e não juntas, como divulgou Afonso d'Escragnole Taunay, baseado no êrro de algumas biografias francesas, do ilustre membro do Instituto de França, engano que se fundamentou inclusive na variação ortográfica do nome, Imas nunca por sua autoria.

Le Breton foi, pois, o planejador da vinda da Missão Artísti.ca Francesa de 1816 ao Brasil e da criação de uma êstola superior de artes e de ofícios no Rio de Janeiro. Tive oportunidade de,publicar seu plano, a respeito desta última, na Revista do Patrimônio Histórico e Artístico Nacional n. ${ }^{\circ}$ 14, traduzindo manuscrito original, inédito, do próprio Le Breton, ainda conservado no Arquivo Histórico do Itamaratí.

A única obra impressa de Le Breton vertida para o nosso idioma, até hoje, é a Notícia Histórica da Vida e das Obras de José Haydn...

"Lida na sessão pública de 6 de outubro de 1810 por Joaquim Le Breton"... "Traduzida em português por um amador e dedicada ao senhor Segismundo Neuknm...". Rio de Janeiro, na Impressão Régia. MDCCCXX.

Mercedes Reis Pequeno, da Biblioteca Nacional do Rio de Janeiro, com aparente razão, atribuiu a autoria da tradução a Baltazar da Silva Lisboa, que não surge entre os subscritores da obra. Sou da mesma opinião.

Essa Notícia fôra um dos muitos elogios históricos lidos por Le Breton em sessões do Instituto de França. Alguns, dos quais exemplos magníficos para se compreender a ideologia neoclássica vigente nos períodos revolucionário e napoleônico, na Europa, como os elogios de Vien, de Pajou e de Houdon.

Com o intuito de tornar mais conhecido o Decreto de D. João VI, que veio a ser a primeira conclusão dos esforços de Le Breton no Brasil e se insere na História de nosso pais como um dos pontos essenciais do capítulo referente à Missão Artística Francesa de 1816, permito-me divulgar, a seguir, o seu texto, nesta Revista. 




"Retrato de Joaquim Le Breton", chefe da Missão (por François Gérard). 
Decreto de 12 de agôsto de 1816, que criava uma Escola Real das Ciências, Artes e Ofícios e fixava as pensões anuais devidas aos respectivos professôres e funcionários.

"Atendendo ao bem comum que provem aos meus fiéis vassalos de se estabelecer no Brasil uma Escola Real de Ciências, Artes e Ofícios, em que se promova e difunda a instrução e conhecimentos indispensáveis aos homens destinados não só aos empregos públicos da administração do Estado, mas também ao progresso da agricultura, mineralogia, indústria e comércio, de que resulta a subsistência, comodidade e civilização dos povos, maiormente neste Continente, cuja extensão, não tendo ainda o devido e correspondente número de braços indispensáveis ao amanho e aproveitamento do terreno, precisa dos grandes socorros da estatística para aproveitar os produtos, cujo valor e preciosidade podem vir a formar do Brasil o mais rico e opulento dos Reinos conhecidos; fazendo-se portanto necessário aos habitantes o estudo das Belas Artes com aplicação e referência aos ofícios mecânicos, cuja prática, perfeição e utilidade depende dos conhecimentos teóricos daquelas artes e difusivas luzes das ciências naturais, físicas e exatas; e querendo para tão úteis fins aproveitar desde já a capacidade, habilidade e iciência de alguns dos estrangeiros beneméritos, que tem buscado a minha real e graciosa proteção para serem empregados no ensino e instrução pública daquelas artes: Hei por bem, e mesmo enquanto as aulas daqueles conhecimentos, artes e oficios não formam a parte integrante da dita Escola Real das Ciências, Artes e Ofícios que eu houver de mandar estabelecer; se pague anualmente por quartéis a cada uma das pessoas declaradas na relação inserta neste meu real decreto, e assinado pelo meu Ministro e Secretário de Estados dos Negócios Estrangeiros e da Guerra, a soma de 8:032\$000 em que importam as pensões, de que por um efeito da minha real munificência e paternal zêlo pelo bem público dêste Reino, lhes faço mercê para a sua subsistência, pagas pelo Real Erário, cumprindo desde logo cada um dos iditos pensionários com as obrigações, encargos e estipulações que devem fazer a base do contrato, que ao menos pelo tempo de seis anos hão de assinar, obrigando-se a cumprir quanto fôr tendente ao fim da proposta instrução nacional, das belas artes, aplicadas à indústria, melhoramentos e progresso das outras artes e oficios mecânicos. O Marquês de Aguiar, do Conselho de Estado, Ministro Assistente ao Despacho, encarregado interinamente da Repartição dos Negócios Estrangeiros e da Guerra, assim o tenha entendido, e faça executar com os despachos necessários. Palácio do Rio de Janeiro, 12 de agôsto de 1816". Com a rubrica de Sua Majestade. 
Relação das pessoas a quem por decreto desta data manda Sua Majestade dar as pensões anuais abaixo declarada. Ao Cavaleiro Joaquim Lebreton ........... 1:600\$000 Pedro Dillon ...................... $\quad \mathbf{8 0 0 \$ 0 0 0}$ João Batista De Bret, pintor de história ...... $\mathbf{8 0 0} \$ 000$ Nicolau Antônio Taunay, pintor .......... $\mathbf{8 0 0 \$ 0 0 0}$ Augusto Taunay, escultor .............. $\mathbf{8 0 0} \$ 000$ A. H. V. Grandjean, arquiteto ........... $\mathbf{8 0 0 \$ 0 0 0}$ Simão Pradier, abridor ............... $\mathbf{8 0 0} \$ 000$ Francisco Ovide, professor de mecânica ..... $800 \$ 000$ C. H. Levasseur . . . . . . . . . . . . . . . $320 \$ 000$ L. Simp. Meunié .................. $320 \$ 000$ F. Bonrepos ...................... $192 \$ 000$

Somam as onze parcelas oito contos e trinta e dois mil réis $(8: 032 \$ 000)$.

\section{MÁRIO BARATA}

Professor de História da Arte da Escola Nacional de Belas Artes da Universidade do Brasil e Professor de História das Artes Modernas na Escola dos Museus, do Museu Histórico Nacional. 